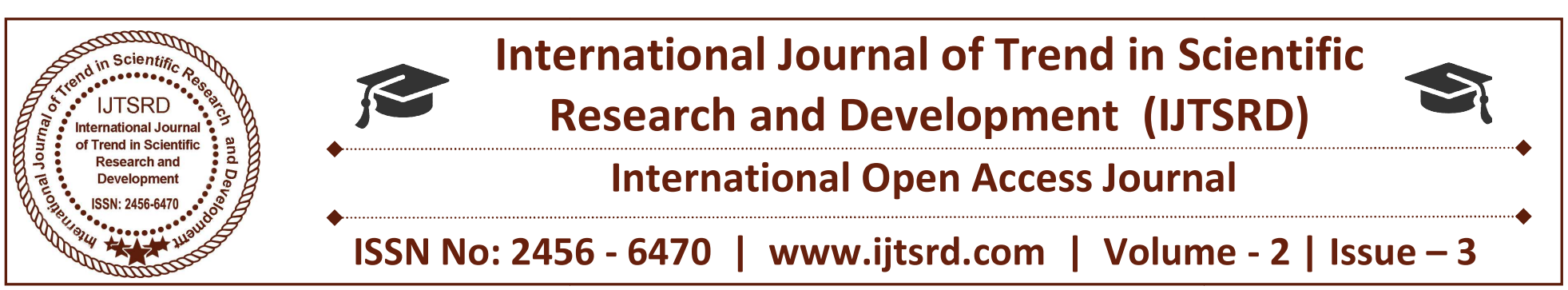

\title{
Stock Prediction System Based on Key Statistics for S\&P 500 With Linear SVC
}

\author{
G. Saminath Krisna, Dr. R. Indra Gandhi \\ Department of Computer Science, GKM College \\ of Engineering and Technology, Chennai, Tamil Nadu, India
}

\begin{abstract}
Previous research shows strong evidence that traditional regression- based predictive models face significant challenges in predictability tests due to uncertain models and unstable parameters. Recent studies introduce new, stable strategies to overcome these problems. Support Vector Clustering is a relatively new learning algorithm that has the desirable characteristics of the control of the decision function, the use of the kernel method, and the sparsity of the solution. In this paper, we present a theoretical and empirical framework to apply the Support Vector Machines strategy to predict the stock market. There are many factors like macro and microeconomic events that may influence the stock trend. For predicting the stock performance, Support Vector Machine is used to analyze the relationship between these factors. Our results suggest that support vector clustering is a powerful predictive tool for stock predictions in the financial market.
\end{abstract}

Keywords: Stock prediction, predictive models, predictive algorithms and training data

\section{INTRODUCTION}

Quantitative trading using artificial intelligence and machine learning algorithms is raising much interest recently. Machine learning algorithms leveraging Big Data and novel hardware can form the basis for effective stock price movement reasoning and artificial intelligent trading decision making. Machine learning algorithms are becoming better at various tasks from manual to cognition. This gives traders a wide range of new insights and opportunities to combine prior knowledge of financial market with non-observable information into trading strategies. These algorithms can accurately predict the fluctuation of stock price bring huge underlying income for fund managers and financial investors. Machine learning algorithms leveraging big data are able to form the basis for effective stock price prediction and trading decision making, so quantitative trading algorithms using machine learning and data mining technologies have been raising much interest these years. Consequently, a wide range of new insights and opportunities are provided for the traders to combine prior knowledge of finance with non-observable information.

\section{REVIEW OF LITERATURE}

The review of various works brings out various interesting facts. There are several studies that apply data mining and analysis tools to investigate the predictability of various financial series.

The reasons quoted for applying data mining tools are its ability to handle voluminous data and nontrivial extraction of implicit, previously unknown, and potentially useful information from financial data. The literature review point out the fact that results of prediction varies among different financial markets. The other interesting fact is that data mining tools are found to consistently outperform other statistical approaches. The literature suggests that data mining tools are likely to predict stock market price movements better when compared to other methods. . The most obvious advantage of the data mining techniques is that they can outperform the classical 
statistical methods with $520 \%$ higher accuracy rate. Majority of the studies incorporated technical factors, intraday movements and macro-economic indicators as input factors for predicting the stock price movements. However, not many studies are concerned with including the global cues and its influence on predicting the stock index movements. Higher evolutionary computing tools like Random Forest and SVM, increased the efficiency of prediction from KNN and ANN with use of. About $60 \%$ of the articles used feed forward neural networks and recurrent networks. The literature review highlights that both statistical and nonstatistical measures were used to evaluate the efficiency of the data mining approaches adopted by researchers. The review of previous works showed that the earlier works undertaken are highly empirical and it is inferred that new research works in new markets at different time periods are likely to show new results and insights. The review also points out that not many studies have been undertaken in Indian and other emerging market economies. Also a comprehensive comparative analysis of the above markets is not undertaken using a data mining approach. The selection of tools initially started from ANN, and moved to Support Vector machines. The SVC (Support Vector Clustering) method was not used for prediction of stock market trend in many studies. Hence an attempt to use successful SVC and other data mining tools to evaluate the predictability of financial markets.

\section{MAJOR STAGES}

1) Data Acquisition

2) Feature extraction

3) Getting current data

4) Prediction

Stock prediction is one of the important applications of machine learning that has elevated in recent years. Stock prediction process depends upon number of factors like economic factors, rumours, investors sentiments, management quality fundamental statistics, etc and these factors influence the movement of stock price. There are four different phases in a stock prediction system, namely: Data acquisition, feature extraction, getting current data and prediction.

\section{DATA ACQUISITION}

Data acquisition is the first stage is the stock prediction system. The data can be acquired either by parsing a stock quote website or by using a data providing service like quandl. The data acquired by parsing websites are stored as html files in the system and os walk is used to acquires the data within the web pages. The webpages are then analysed to find the required data. The acquired data is then stored in a $\operatorname{csv}$ (comma separated value) file. If the data is acquired from data providers like Quandl or Bloomberg then, the data comes by default in the csv format. So if you are using data providers to get your data, then data acquisition becomes much easier.

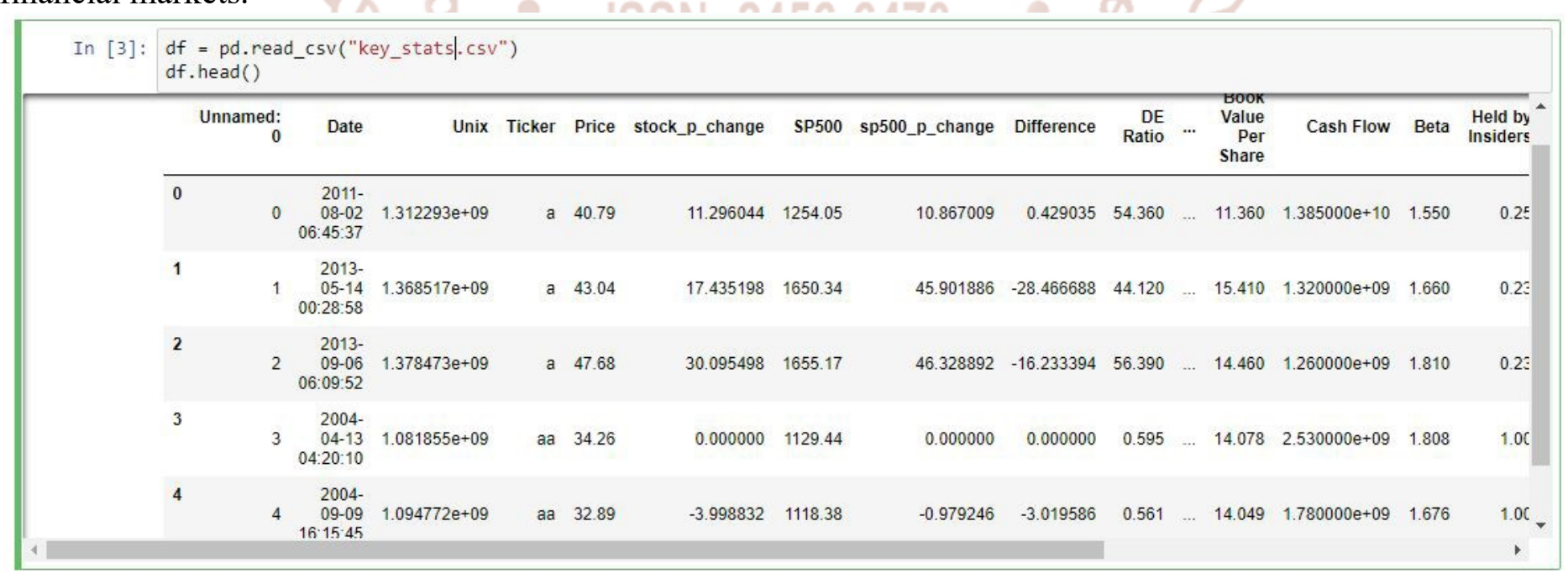

\section{Parsing data from websites}

There are many frameworks and libraries available for parsing websites. Read the documentation of the website carefully before parsing it. Some websites do not allow developers to parse the websites without permission. The most common library for python to parse websites is beautiful-soup-4. There are also many other good libraries available for python which makes it easy to parse websites. The parsed websites can be stored in the system based on the system based on the ticker symbol and date. 


\begin{tabular}{|c|c|c|c|}
\hline \multicolumn{2}{|l|}{ Key Statistics } & Get Key Statistics for: & GO \\
\hline \multicolumn{4}{|c|}{$\begin{array}{l}\text { Data provided by Capital IQ, except } \\
\text { where noted. } \\
\text { Valuation Measures }\end{array}$} \\
\hline \multirow{2}{*}{$\begin{array}{l}\text { Market Cap (intraday) } \\
\text { Enterprise Value (Oct } 8 \text {, } \\
2011)^{3} \text { : }\end{array}$} & $342.84 \mathrm{~B}$ & & \\
\hline & $314.44 \mathrm{~B}$ & & \\
\hline \multirow{2}{*}{$\begin{array}{l}\text { Trailing P/E (ttm, intraday): } \\
\text { Forward P/E (fye Sep 25, } \\
\text { 2012): }\end{array}$} & 14.63 & & \\
\hline & 11.28 & & \\
\hline \multirow{5}{*}{$\begin{array}{l}\text { PEG Ratio (5 yr expected)': } \\
\text { Price Sales (ttm): } \\
\text { Price Book (mrq): } \\
\text { Enterprise Value Revenue } \\
(\text { ttm })^{3} \text { : } \\
\text { Enterprise Value EBITDA } \\
(t \mathrm{~m})^{5} \text { : }\end{array}$} & 0.59 & & \\
\hline & 3.49 & & \\
\hline & 5.04 & & \\
\hline & 3.13 & & \\
\hline & 9.80 & Trading Information & \\
\hline \multicolumn{2}{|l|}{ Financial Highlights } & Stock Price History & \\
\hline \multicolumn{2}{|l|}{ Fiscal Year } & Beta: & 0.87 \\
\hline \multicolumn{2}{|l|}{ Fiscal Year Ends: } & 52-Week Change': & $25.75 \%$ \\
\hline \multirow{2}{*}{\multicolumn{2}{|c|}{ Most Recent Quarter (mrq): }} & S\&P500 52-Week Change': & $-0.83 \%$ \\
\hline & & 52-Week High (Sep 20, 2011) & 422.86 \\
\hline \multicolumn{2}{|l|}{ Profitability } & 52-Week Low (Oct 8, 2010) ${ }^{3}$ : & 290.00 \\
\hline Profit Margin (ttm): & $23.53 \%$ & 50-Day Moving Average : & 385.15 \\
\hline Operating Margin (ttm): & $30.43 \%$ & 200-Day Moving Average?: & 358.93 \\
\hline \multicolumn{2}{|c|}{ Management Effectiveness } & Share Statistics & \\
\hline Return on Assets (ttm): & $22.25 \%$ & Avg Vol (3 month) & $22,498,100$ \\
\hline Return on Equity (ttm): & $41.99 \%$ & Avg Vol (10 day $)^{3}$ : & $24,992,700$ \\
\hline \multicolumn{2}{|l|}{ Income Statement } & Shares Outstandings: & $927.09 \mathrm{M}$ \\
\hline Revenue (ttm): & $100.32 \mathrm{~B}$ & Float: & $921.05 \mathrm{M}$ \\
\hline Revenue Per Share (ttm): & 108.95 & $\%$ Held by Insiders : & $0.65 \%$ \\
\hline Qtrly Revenue Growth (yoy): & $82.00 \%$ & $\%$ Held by Institutions': & $70.80 \%$ \\
\hline \multirow{4}{*}{$\begin{array}{l}\text { Gross Profit (ttm): } \\
\text { EBITDA (tmm) } \\
\text { Net Income Avl to Common } \\
(\mathrm{ttm}) \text { : }\end{array}$} & $25.68 \mathrm{~B}$ & Shares Short (as of Sep 15, & \\
\hline & $32.08 \mathrm{~B}$ & $2011)^{9}:$ & $14.33 \mathrm{M}$ \\
\hline & $23.61 \mathrm{~B}$ & Short Ratio (as of Sep 15, 2011) ${ }^{3}$ : & $=0.80$ \\
\hline & 25.28 & $\begin{array}{l}\text { Short \% of Float (as of Sep 15, } \\
2011)^{3} \text { : }\end{array}$ & $\mathrm{N} / \mathrm{A}$ \\
\hline $\begin{array}{l}\text { Diluted EPS (ttm): } \\
\text { Qtrly Earnings Growth (yoy) }\end{array}$ & $124.70 \%$ & Shares Short (prior month) & $15.16 \mathrm{M}$ \\
\hline \multicolumn{2}{|c|}{ Balance Sheet } & Dividends \& Splits & \\
\hline Total Cash (mrq): & $28.40 \mathrm{~B}$ & Forward Annual Dividend Ratet: & $\mathrm{N} / \mathrm{A}$ \\
\hline Total Cash Per Share (mrq): & 30.63 & Forward Annual Dividend Yield": & $\mathrm{N} / \mathrm{A}$ \\
\hline Total Debt (mrq): & 0.00 & Trailing Annual Dividend Yield?: & $\mathrm{N} / \mathrm{A}$ \\
\hline Total Debt Equity (mrq): & N/A & Trailing Annual Dividend Yield ${ }^{3}$ : & $\mathrm{N} / \mathrm{A}$ \\
\hline Current Ratio (mrq): & 1.75 & & $\mathrm{~N} / \mathrm{A}$ \\
\hline Book Value Per Share (mrq): & 74.81 & S rear Average Dridend rield: & N/A \\
\hline \multicolumn{2}{|c|}{ Cash Flow Statement } & Payout Katio": & $N / A$ \\
\hline \multirow{3}{*}{$\begin{array}{l}\text { Operating Cash Flow (ttm): } \\
\text { Levered Free Cash Flow } \\
\text { (ttm): }\end{array}$} & $32.78 \mathrm{~B}$ & & Nov 21 \\
\hline & $21.47 \mathrm{~B}$ & Ex-Dividend Date & $\begin{array}{l}\text { Nov } 21, \\
1995\end{array}$ \\
\hline \multirow{2}{*}{\multicolumn{2}{|c|}{$\begin{array}{c}\text { View Financials } \\
\frac{\text { Income Statement - Balance Sheet - }}{\text { Cash Flow }}\end{array}$}} & Last Split Factor (new per old)2: & $2: 1$ \\
\hline & & Last Split Date? & $\begin{array}{l}\text { Feb 28, } \\
2005\end{array}$ \\
\hline
\end{tabular}

Data providers are corporations which sell data in exchange for money. There are lot of companies that sell data with different subscription models. Some of the well known websites for getting data are Quandl and bloomberg. The OHLC data can be acquired for free from many websites. But for this project we need the fundamental statistics of all the companies in $s \& p$ 500. For that we have to subscribe to any of the above mentioned data providers. They also have API (Application Programming Interface) and JSON (Javascript Object Notation) modes to get data other than CSV (Comma Separated Values).

\section{FEATURE EXTRACTION}

Munging is the process of clearing out the redundant information from the obtained data. If the data is obtained by parsing websites, then this process becomes much more complicated. The data obtained from data providers are usually pre processed and the redundant data is removed at the source. The important features are extracted in this stage. If we are using an API for getting data from the data provider, then we can specifically get the required data. The parsed data should also be stored in the csv or table format to process it using pandas. The pandas library 
converts the csv file into a dataframe and the supervised form of learning. So the data has to be dataframe is used for further processing. SVC is a labeled as either outperforming or underperforming.

\begin{tabular}{|c|c|c|c|c|c|c|c|c|c|c|c|c|c|c|c|c|}
\hline ce & stock_p_change & SP500 & sp500_p_change & Difference & $\begin{array}{r}\mathrm{DE} \\
\text { Ratio }\end{array}$ & $\ldots$ & $\begin{array}{r}\text { Book } \\
\text { Value } \\
\text { Per } \\
\text { Share }\end{array}$ & Cash Flow & Beta & $\begin{array}{l}\text { Held by } \\
\text { Insiders }\end{array}$ & $\begin{array}{r}\text { Held by } \\
\text { Institutions }\end{array}$ & $\begin{array}{r}\text { Shares } \\
\text { Short (as } \\
\text { of }\end{array}$ & $\begin{array}{l}\text { Short } \\
\text { Ratio }\end{array}$ & $\begin{array}{l}\text { Short } \\
\% \text { of } \\
\text { Float }\end{array}$ & $\begin{array}{r}\text { Shares } \\
\text { Short } \\
\text { (prior }\end{array}$ & Status \\
\hline 79 & 11.296044 & 1254.05 & 10.867009 & 0.429035 & 54.360 & $\ldots$ & 11.360 & $1.385000 \mathrm{e}+10$ & 1.550 & 0.25 & 82.10 & 4360000.0 & 1.200 & 1.40 & 5420000.0 & outperform \\
\hline 04 & 17.435198 & 1650.34 & 45.901886 & -28.466688 & 44.120 & $\ldots$ & 15.410 & $1.320000 \mathrm{e}+09$ & 1.660 & 0.23 & 83.20 & 4370000.0 & 1.200 & 1.30 & 3080000.0 & underperform \\
\hline 68 & 30.095498 & 1655.17 & 46.328892 & -16.233394 & 56.390 & $\ldots$ & 14.460 & $1.260000 \mathrm{e}+09$ & 1.810 & 0.23 & 83.50 & 2780000.0 & 1.200 & 0.80 & 3300000.0 & underperform \\
\hline 26 & 0.000000 & 1129.44 & 0.000000 & 0.000000 & 0.595 & $\ldots$ & 14.078 & $2.530000 \mathrm{e}+09$ & 1.808 & 1.00 & 79.36 & 12540000.0 & 2.497 & 1.46 & 12700000.0 & underperform \\
\hline 89 & -3.998832 & 1118.38 & -0.979246 & -3.019586 & 0.561 & $\ldots$ & 14.049 & $1.780000 \mathrm{e}+09$ & 1.676 & 1.00 & 76.64 & 7780000.0 & 1.935 & 0.90 & 7930000.0 & underperform \\
\hline
\end{tabular}

\section{GETTING CURRENT DATA}

The current data can either be acquired using parsing yahoo finance or from a data provider. If you are subscribed to a data provider, they can provide you with daily OHLC prices and quarterly key statistics. If you are using web parsing to get the data, you should parse the website once every 3 months, and update your stock list. Data providers update their technical data on a daily basis, with quarterly release of fundamental data.

\section{SUPPORT VECTOR MACHINES}

SVM is a supervised machine learning model with associated learning algorithms that are used for analyzing and predicting probabilities, using the given data. It used to perform classification and regression analysis on the given structured and unstructured data. SVM is a non-probabilistic linear classifier. Given a labeled set of training examples, each marked as belonging to one or the other. The SVM training algorithm builds a model that assigns new examples to one category or the other. It is a representation of the examples as points in space, mapped so that the data points are separated clearly. Additional new data plots are then incorporated into that same space. Based on where the point falls on, it is added to specific categories. Support Vector Machines can also perform non linear classification using the kernel trick.

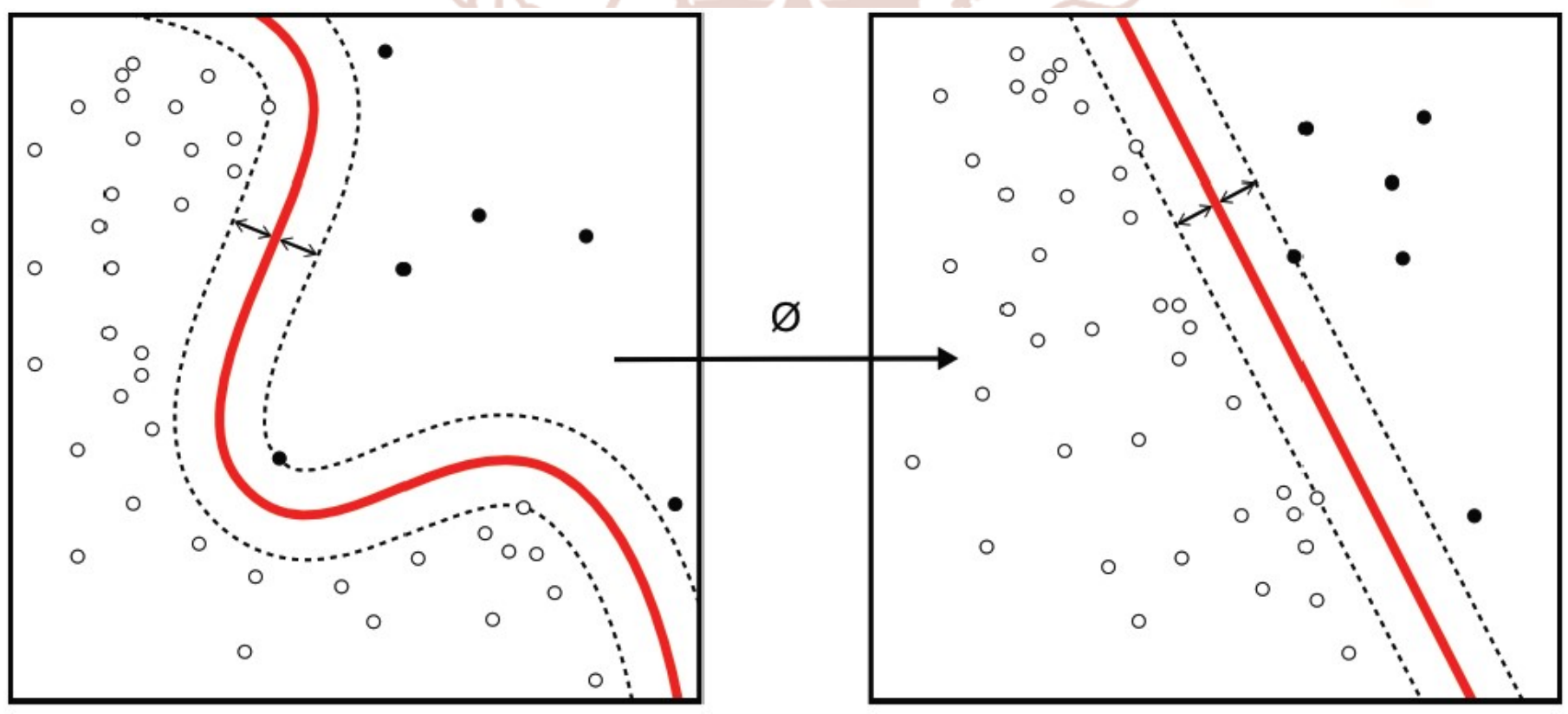




\section{SUPPORT VECTOR CLUSTERING}

Clustering is to partition a data set into different groups according to some criterion in an attempt to organize data into a more meaningful form. There are many ways of achieving this form. Clustering may proceed according to some parametric model or by grouping data points according to some distance or similarity measure as in hierarchical clustering. It usually adds cluster boundaries within regions of the data space where there is insufficient data in the probability distribution area. This is the path taken in support vector clustering, which is based on the support vector approach.
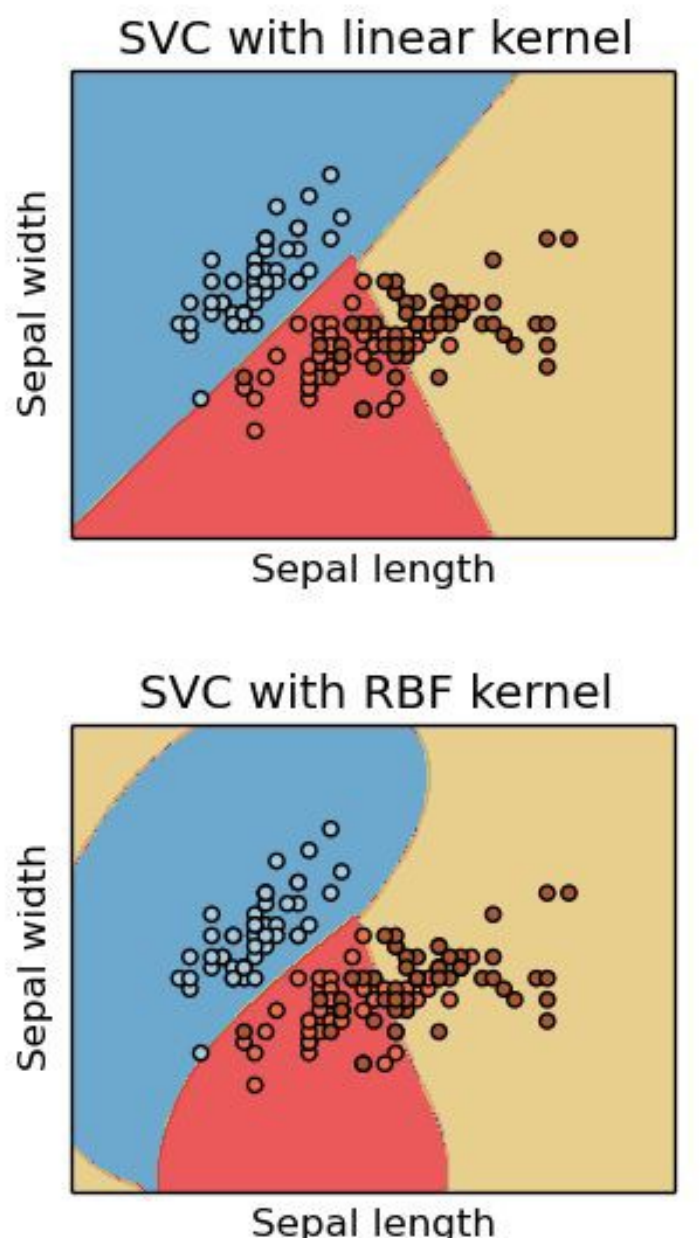

\section{PREDICTION}

The multidimensional and multivariate data is then structured and passed to the prediction model. Linear Support Vector Clustering algorithm is used for predicting the future price of the stock. We can also compare the predicted stock's performance with the s\&p 500 benchmark.
In SVC data points are mapped from data space to a high dimensional feature space using the kernel function. In feature space we look for the smallest sphere that encloses the image of the data points using the Support vector domain description algorithm (DDA). This sphere, when mapped back into the data space, will form a set of contours which can enclose the data points. We interpret these contours as cluster boundaries, and points enclosed by each contour are associated by support vector clustering to the same cluster.
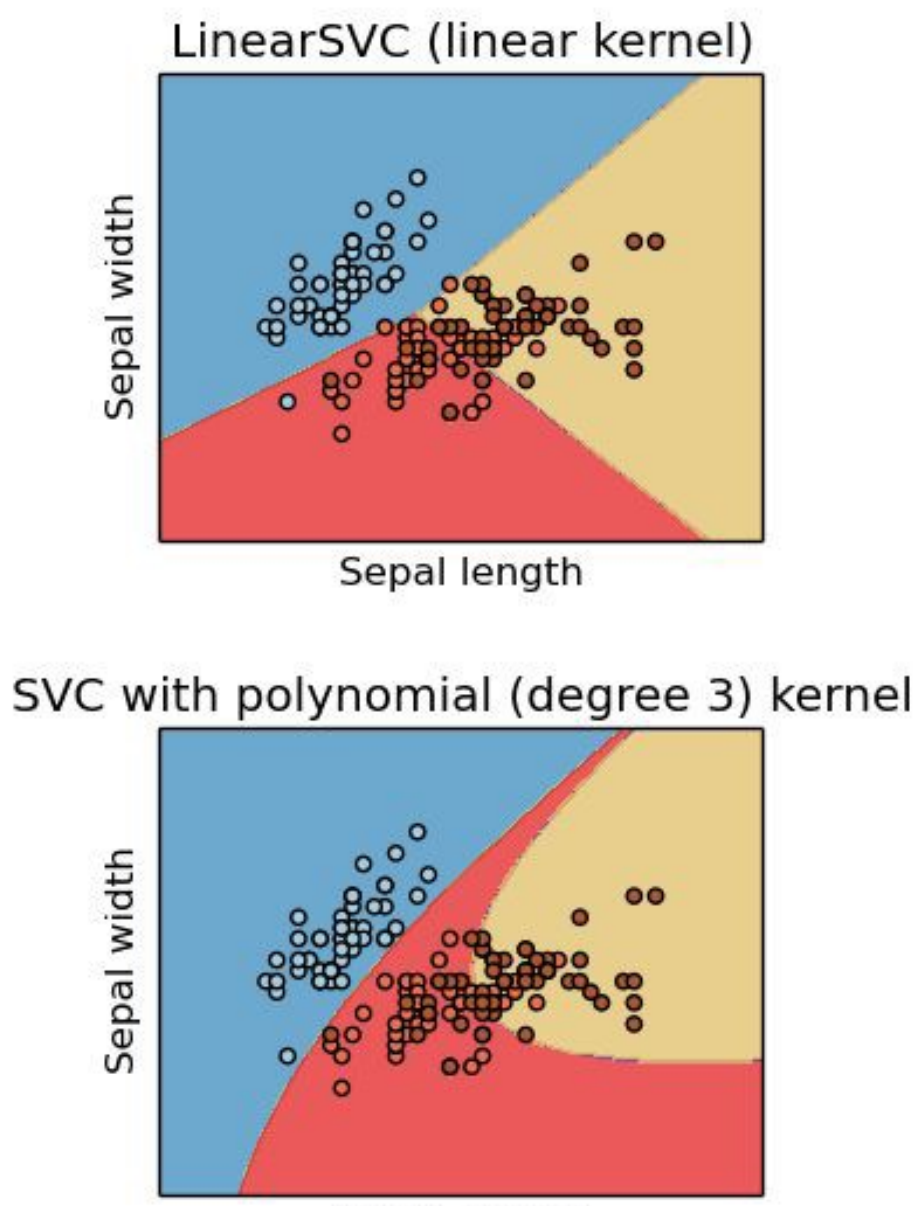

Sepal length

The accuracy of prediction and the percentage gain of the predicted stock compared to the benchmark can be interpreted. 
Select the stock

FMC Corporation -

Ticker Symbol: FMC

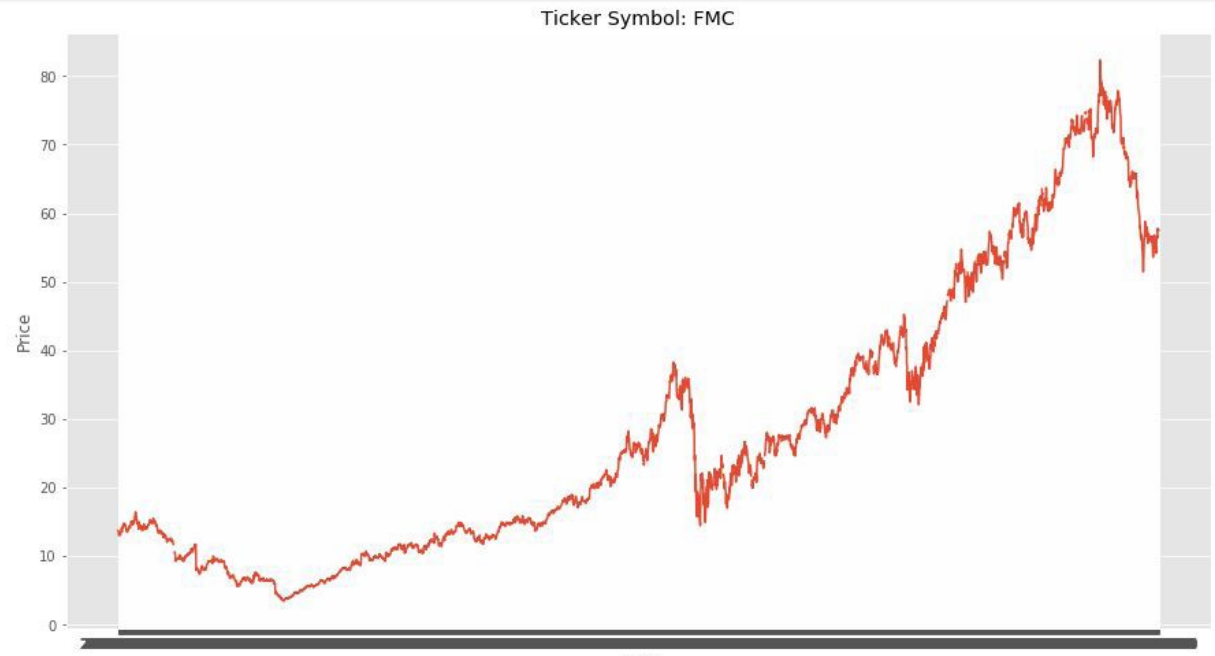

\section{CONCLUSION}

This paper proposes a SVM-based stock market trend prediction system based on the fundamental statistics and stock prices to predict the long term movement of the stock. The system takes into account a good feature subset, which contains features that are highly correlated with the output, yet uncorrelated with each other. The selected features are evaluated carefully and prioritized. The feature selection and feature evaluation are filtered by correlation-based SVM. It reduces dimension and noise of financial data as well as provides pre selected stocks for experts and investors to make a investing decision. In the proposed system, the setting of parameters have a critical impact on the performance of the resulting system. We need to investigate to develop a structured method of selecting an optimal value for the parameters in the proposed prediction system for the best results.

\section{REFERENCES}

1. Y. Boykov, O. Veksler, and R. Zabih. Fast approximate energy minimization via graph cuts. In Proc. of the International Conference on Computer Vision (ICCV), 1999.

2. K. Crammer and Y. Singer. On the algorithmic implementation of multiclass kernel-based vector machines. The Journal of Machine Learning Research, 2:265-292, 2002.

3. K. M. Cremers and A. Petajisto. How active is your fund manager? a new measure that predicts performance. Review of Financial Studies, 22(9):3329-3365, 2009.

4. C.-M. Hsu. A hybrid procedure for stock price prediction by integrating self-organizing map and genetic programming. Expert Systems with Applications, 38 (11):14026-14036, 2011

5. S. Gould. Learning weighted lower linear envelope potentials in binary markov random fields. IEEE transactions on pattern analysis and machine intelligence, 37(7):1336-1346, 2015.

6. W. Huang, Y. Nakamori, and S.-Y. Wang, "Forecasting stock market movement direction with support vector machine," Computers and Operations Research, vol. 32, pp. 2513-2522, 2005.

7. J. D. Piotroski, "Value investing: The use of historical financial statement information to separate winners from losers," Journal of Accounting Research, vol. 38, pp. 1-41, 2000. 